\title{
PANDEMIA: ¿EN QUÉ MODIFICA Y EN QUÉ RATIFICA NUESTRO MODELO DE DESARROLLO?
}

\author{
Álvaro Fischer Abeliuk
}




\section{ÁLVARO FISCHER ABELIUK}

Ingeniero matemático de la Universidad de Chile. Es emprendedor, director de empresas $\mathrm{y}$ escritor ensayista. Es fundador y director de Resiter S.A., grupo de empresas de servicios tecnológicos ambientales, y presidente de SMB Factoring. Ha sido director de Farmacias Ahumada, Salcobrand, Cruz Blanca y Empresas Copec S.A. Fue presidente del Instituto de Ingenieros de Chile (Premio al Ingeniero por Acciones Distinguidas 2002) y de Fundación Chile.

Actualmente se desempeña como presidente del Consejo Nacional de Ciencia, Tecnología, Conocimiento e Innovación. Es miembro del directorio de la Fundación Imagen de Chile, presidente de la Fundación Ciencia y Evolución y representante del Presidente de la República en el consejo universitario de la Universidad de Chile. Es integrante de la New York Academy of Science y de la Human Behavior and Evolution Society. En el año 2001 publicó Evolución... el nuevo paradigma, en 2009 La mejor idea jamás pensada y, en enero de 2018, De naturaleza liberal. 


\section{PANDEMIA: ¿EN QUÉ MODIFICA Y EN QUÉ RATIFICA NUESTRO MODELO DE DESARROLLO?}

\section{INTRODUCCIÓN}

En todos los lugares donde la pandemia de Covid-19 ha brotado, han surgido preguntas similares: de índole biológica o epidemiológica cuando se analiza la enfermedad como tal; de orientación económica o sociológica cuando se atiende a las consecuencias que ella provoca; de inclinación ética o filosófica cuando los dilemas morales envueltos o las angustias generadas relativas al futuro conducen a replanteamientos respecto del sentido de la vida, que se ha revelado más frágil de lo que el siglo XXI parecía sugerir.

Chile no ha sido una excepción.

La variedad de temáticas recién mencionadas dificulta encontrar la organización conceptual adecuada para un análisis comprensivo y coherente del escenario producido. ¿De qué manera la pandemia modifica la comprensión de los fenómenos sociales modernos y de qué manera los ratifica y, como consecuencia de ello, en qué modifica o en qué ratifica nuestro modelo de desarrollo? ¿Con qué marco conceptual es posible hacer esas distinciones?

En este documento propongo hacer un ejercicio que intente responder a esas preguntas, para luego abordar las modificaciones o ratificaciones que se deba incorporar al modelo de desarrollo del país, acorde con ellas. Para eso, he considerado pertinente utilizar la distinción entre información biológica e información cultural. La primera define aquellos rasgos más permanentes de la especie humana - sistema cognitivo, sistema emocional y psicología moral- encriptados en el genotipo de la especie y esculpidos evolutivamente por selección natural. La segunda es aprendida socialmente durante la vida de los individuos, acumulada a lo largo de siglos de proceso civilizatorio, y conforma la parte más visible de las sociedades contemporáneas. De las regularidades que ambas normalmente exhiben será posible advertir cuáles de ellas, si las hay, han sido modificadas por la pandemia y cuáles no.

Como metodología de análisis propondré la perspectiva evolucionaria aplicada a las ciencias sociales como el marco conceptual apropiado para abordar esta reflexión, utilizaré al conocimiento como el rasgo definitorio de las sociedades modernas en un sentido que procuraré precisar y, sobre la base de las características que este les confiere y los rasgos de los individuos que las componen, intentaré responder la pregunta con que titulé este ensayo. 


\section{MARCO CONCEPTUAL}

\section{Natura y cultura}

Los seres humanos, al igual que el resto de los organismos vivos, transmiten de una generación a otra, mediante el proceso reproductivo, los rasgos más característicos de su especie. Esos rasgos se adquirieron, esculpieron y moldearon evolutivamente por selección natural (Cosmides y Tooby, 1992; Pinker, 1994). Son los que han dado lugar a nuestro sistema cognitivo - los mecanismos de procesamiento de información sustentados en el sistema nervioso central—, nuestro sistema emocional - los algoritmos mentales que, a partir de las pistas que entrega el entorno, generan ciertos cursos de comportamiento en vez de otros- y nuestra psicología moral, es decir, aquellas capacidades mentales que usamos para hacer distinciones y juicios que llamamos morales (Greene, 2013). Estos sistemas constituyen la parte más sustantiva de aquello que denominamos naturaleza humana y se expresan a través de la arquitectura neuronal del sistema nervioso central. La información que guarda esa arquitectura está encriptada en el genotipo de la especie y se traspasa intergeneracionalmente.

Hay otro tipo de información, sin embargo, cuyo mecanismo de traspaso es intrageneracional, pues se adquiere a lo largo de la vida de las personas por medio del aprendizaje, la enseñanza o la imitación, y que no se encuentra encriptada en el genotipo de la especie (Mosterín, 2008). Esta información recibe el nombre de cultura y se va acumulando y modificando a través del tiempo, en una deriva que denominamos evolución cultural, que ocurre a una velocidad mucho mayor que la de la selección natural. Los ejemplos más salientes de información cultural son los códigos legales, penales y morales, las tecnologías de diversa índole, las teorías científicas, las obras de arte, las creencias religiosas, la historia, la filosofía, la matemática y las costumbres, entre muchas otras. En algunos casos, ella tiene características locales - las tradiciones culinarias, artísticas, históricas o el dialecto de un territorio específico-y en otros casos, globales, como las tecnologías digitales, la matemática o los procesos industriales.

De lo anterior se sigue que los seres humanos no están determinados ni genética ni culturalmente (Wilson, 2014). Son más bien el resultado del encuentro entre las herramientas mentales con las que disciernen su comportamiento diario y estratégico, biológicamente heredadas, con el entorno al que se enfrentan, socialmente adquirido, el que cada vez más es cultural y no geográfico, producto del propio desarrollo humano a través del tiempo.

Hay una amplia literatura científica que respalda las aseveraciones aquí hechas, algunas de las cuales se acompañan en las referencias. 


\section{Sociedad del conocimiento}

La historia de los seres humanos es tan compleja como complejas son sus motivaciones. A pesar de ello, es posible extraer un patrón que se ha mantenido a lo largo de los milenios. De manera genérica, podría caracterizarse como "progreso", pero como ese término tiene distintas connotaciones, incluso políticas, no resulta apropiado en este contexto. Si ese patrón lo expresamos en términos físicos, corresponde al permanente aumento de la energía que los humanos logran poner a disposición de sí mismos, normalizado por unidad de masa y por unidad de tiempo; si lo decimos en términos económicos, corresponde a la permanente creación de valor en la que se involucran los humanos, entendida como la provisión de bienes, servicios o formas de organización de diversa índole que resulten más valiosas para quienes participan de ellas; finalmente, dicho en términos más cercanos a la actividad diaria, se trata de la búsqueda de mejores condiciones de vida para cada quien o para su comunidad, entendida esta última desde los entornos más cercanos hasta todos los habitantes del planeta.

Desde la época de los cazadores-recolectores de hace cientos de miles de años - que desarrollaron las primeras hachas de mano, desbastando una piedra contra otra mediante precisos y diestros cortes, aprendiendo y perfeccionando un conocimiento valioso para cortar objetos, hacer incisiones, agredir o defenderse de animales y enemigos - hasta la sociedad digital contemporánea, caracterizada por conocimiento científico y tecnológico empaquetado - celulares, computadores, realidades virtuales o aumentadas, entre tantas otras-, los seres humanos han estado constantemente motivados por proveerse de bienes y prestar servicios que procuren generar valor de manera creciente.

Ese proceso estuvo inicialmente basado en el trabajo manual y la fuerza física, complementado luego - dados los beneficios que confiere a la creación de valor- por el intercambio, la división del trabajo y la organización institucional. Luego, parte de ese trabajo comenzó a ser desplazado progresivamente por objetos construidos por humanos, ingeniosos inventos que también agregaron valor al proceso involucrado. De esa manera, lentamente primero y aceleradamente después, el elemento distintivo que caracteriza la creación de valor es el conocimiento. Las sociedades modernas se caracterizan, principalmente, por el uso intensivo de conocimiento. Este se basa en ciencia que lo crea, tecnología que lo aplica, innovación que genera valor a partir de ambos, y emprendimiento, que implementa productivamente todo lo anterior. Esa tetralogía constituye una de las piedras angulares que permite impulsar el desarrollo de los países. 


\section{Impulsores del comportamiento e instituciones}

Como hemos dicho, los seres humanos utilizan las herramientas provistas por su sistema cognitivo, emocional y de psicología moral para navegar un entorno que es cada vez menos natural y cada vez más cultural y de significado científico, tecnológico, artístico, deportivo, filosófico, religioso o económico, entre muchos otros. Esas herramientas son las que impulsan y motivan el comportamiento de las personas. Tres de esos impulsores resultan cruciales para la dinámica de las sociedades humanas.

El primero es la dupla altruismo-egoísmo, elementos que se gatillan uno u otro según el contexto al que las personas se enfrenten, como lo muestran numerosos experimentos intensamente estudiados durante los últimos 30 años (Smith, 1998). El hecho de que coexistan siendo opuestos los instala en el corazón de las disputas políticas contemporáneas, lo que constituye uno de los ineludibles dilemas de la condición humana.

El segundo consiste en el persistente esfuerzo de las personas por ascender en la jerarquía social, sea en términos económicos, de prestigio, de poder, de influencia o de estatus, lo que las lleva a competir y a diferenciarse entre sí más que a igualarse. (Tudge, 1998; Sykes, 2005).

El tercero, la psicología coalicional, es la disposición de las personas a conformar grupos dependiendo de distintas afinidades - religiosas, nacionales, deportivas, políticas, etc.- , donde los integrantes se guardan lealtad y consideran a otros grupos como sus adversarios, como si se tratara de un juego suma cero (Cosmides y Tooby, 1988). La psicología coalicional está en la base del tribalismo actual, que se opone a la globalización.

Estos tres impulsores del comportamiento no siempre apuntan en la misma dirección, sino que propician conflictos entre las personas en diferentes sentidos. El resultado de esa dinámica, filtrada por nuestra psicología moral, se traduce en tensiones de diverso tipo, que se expresan en las sociedades y generan la conflictividad que muchas veces las caracteriza.

Pero, además, las sociedades modernas basan su funcionamiento en las instituciones que reglan las conductas admisibles de las personas y determinan la forma en que se gobiernan. Estas procuran combinar la autonomía de los individuos cuya conducta sigue a sus motivaciones, propulsadas por los impulsores conductuales recién descritos- con los objetivos colectivos de la comunidad como un todo.

De ahí que el gran desafío de las sociedades modernas sea diseñar y construir las instituciones que, dados los rasgos que caracterizan el comportamiento de sus integrantes, mejor contribuyan a mantener la trayectoria de creación de valor que los motiva y que les permita satisfacer sus anhelos y metas. 


\section{LA PANDEMIA Y SUS IMPACTOS}

La pandemia de Covid-19, enfermedad provocada por el virus SARS-CoV-2, probablemente originada en un contagio desde un animal a un humano en la ciudad de Wuhan, China, ha impactado a todo el planeta. Al momento de escribir estas líneas (mayo de 2020), hay sobre cinco millones de infectados comprobados, de los cuales algo más de 300 mil han fallecido por su causa.

Este no es un fenómeno ajeno a la historia humana ni menos a la historia de los organismos vivos. Dependiendode si sela analiza macroscópica o microscópicamente, la biósfera puede ser considerada como un gran ejercicio cooperativo o como una despiadada competencia. A escala macro, la mutua dependencia de los diferentes organismos entre sí, que es lo que les permite subsistir, lo ilustra con elocuencia: la flora microbiana que habita nuestro sistema digestivo y nos ayuda a sobrevivir es, a su vez, el hogar para aquella; los sistemas de predadores y presas, complejamente interconectados entre sí, constituyen cadenas en ecológico equilibrio; la mutua dependencia de animales y vegetales, los primeros alimentándose de las segundas, cuyo residuo (CO2) estas luego utilizan para efectuar la fotosíntesis que las mantiene vivas. Todo ello observado en conjunto aparece como una gran cooperación del mundo de lo vivo.

Por otra parte, a nivel micro, la permanente lucha que libra la diversidad de patógenos que atacan a los distintos hospederos en los que habitan y florecen genera una carrera armamentista de adaptaciones cuya batalla se despliega por selección natural. De hecho, la aparición de la reproducción sexuada surgió como una adaptación para otorgar protección contra los patógenos, pues la recombinación genética aleatoria a que esta conduce da lugar a variaciones en los rasgos resultantes, potenciales protectores contra estos. Los seres humanos han llevado esa carrera a otro nivel por medio del conocimiento científico y la tecnología, ya sea farmacológicamente o, como consecuencia de esta pandemia, por medio del distanciamiento social y el seguimiento digital de infectados, que disminuye la velocidad del contagio.

Esta pandemia ha tenido diversos impactos y ha mostrado distintas facetas de las reacciones humanas. Resumiré a continuación los que me parecen más relevantes para el objetivo de este ensayo.

\section{El miedo al contagio}

En su reconocido libro The righteous mind (Haidt, 2012), su autor, psicólogo social, muestra, a través de una acumulación de experimentos a lo largo de las últimas décadas, que los sentimientos morales humanos se organizan, en la versión que 
él entrega, en torno a seis ejes, todos ellos fundados en la respuesta evolutiva de la especie a los distintos desafíos adaptativos que enfrentó durante su pasado cazador-recolector. En particular, uno de ellos, el eje sanidad-degradación, se funda en la respuesta evolutiva al desafío adaptativo de vivir en un mundo plagado de patógenos y parásitos, que nos ha llevado a evitar aquello que tenga aspecto impoluto, sucio o podrido, características que nos generan la emoción de asco o disgusto. El antropólogo Pascal Boyer (Boyer, 2001) adjudica a ese rasgo humano el que casi todas las religiones - probablemente, de manera inconsciente- pongan tanto énfasis en la polución y la limpieza, así como en el lavado de manos y cuerpos.

En el repertorio de sentimientos morales humanos, el miedo al contagio tiene un origen evolucionario y por eso es tan prevalente entre las personas y tan difícil de evitar. De allí que la población de los distintos países tienda a aplaudir cuando los gobiernos decretan cuarentenas y miren con reticencia cuando estos pretenden levantarlas. Es necesario anotar, sin embargo, que si el costo de la cuarentena supera cierto umbral, las personas comienzan a rebelarse contra ella.

\section{Constatación de la intrincadísima interconexión en la que se desenvuelve la economía}

Los seres humanos, al igual que todos los organismos vivos, requieren de energía para mantener la estructura de sus organismos, cuya configuración está fuertemente alejada del equilibrio. El segundo principio de la termodinámica, ley fundamental de la física, así lo obliga.

Los cazadores-recolectores de antaño se levantaban en las mañanas y su única preocupación era conseguir alimento. Una vez logrado este objetivo, podían volver a su campamento, descansar y hacer vida de clan. En cambio, en la enmarañada complejidad de las economías contemporáneas, las personas se levantan en las mañanas a realizar sus actividades sin preocuparse por la obtención de energía, pues asumen, sin siquiera estar conscientes de ello, que otros estarán cultivando, empaquetando, industrializando y transportando los alimentos necesarios para su ingesta, que pueden luego comprar con extrema facilidad. A su vez, quienes participan en la cadena alimenticia confían en que otros estarán preocupados de la provisión de energía, de hacer funcionar los celulares, el Internet, los sistemas de pago, y así, sucesivamente.

Esta intrincada red de intercambios es la que permite que las personas puedan consumir bienes, recibir servicios, informarse, entretenerse o cultivar el intelecto. Se basa en el trabajo coordinado de todos, sin que haya un comando central que los coordine ni menos que los controle, salvo un sistema institucional que regula los 
intercambios, protege los derechos y arbitra los conflictos. La mejor o peor adecuación de su diseño a los rasgos de las personas definirá, finalmente, su grado de éxito.

La pandemia dejó súbitamente al descubierto el enrevesado e invisible entrelazamiento que presenta el funcionamiento de la economía. La imposición del distanciamiento social - atenuado o estricto- para combatir la pandemia, al impedir que el trabajo normal diario siga operando con fluidez, disrumpió gravemente la economía. De pronto, quedó claro que la subsistencia de las sofisticadas economías del siglo XXI requiere de la interdependencia de todos los miembros de la especie. La constatación de esa realidad y de las nefastas consecuencias que resultan cuando ella se disrumpe es una de las clarificaciones que ha traído la pandemia y que más consecuencias ha provocado.

\section{Importancia de la ciencia y la tecnología}

Hay dos formas no excluyentes de combatir la pandemia: la farmacéutica y la social. La primera se caracteriza por el desarrollo de vacunas que prevengan el contagio de la población susceptible o drogas antivirales efectivas que sanen a quienes de todos modos se enfermen. La segunda se basa en el distanciamiento social para atenuar la probabilidad de contagio. Su expresión más sofisticada es tecnológica, mediante el testeo intensivo y permanente que detecta a quienes están contagiados para luego aislarlos selectivamente, geolocalizándolos y utilizando aplicaciones en celulares que ayuden al cumplimiento del distanciamiento.

Tanto el tratamiento farmacéutico como el social-digital requieren de un alto desarrollo científico-tecnológico para ser exitosos.

La secuenciación inicial del virus, lograda a pocos días de descubierto, la identificación de marcadores biológicos que permitieron desarrollar y posteriormente fabricar masivamente los kits de testeo, ya sea del virus mismo o de los anticuerpos que quedan circulando en la sangre, son procesos basados en conocimiento científico sofisticado y en biotecnologías de punta. Lo mismo ocurre con el desarrollo de vacunas y antivirales, que están siendo buscados afanosamente por una multitud de grupos en el mundo, en algunos casos colaborativamente y en otros, competitivamente.

La fabricación masiva de kits de testeo y de máquinas PCR automatizadas precisa de instalaciones productivas especializadas y de alta sofisticación, que solo equipos de científicos y tecnólogos muy preparados pueden construir; asimismo, geolocalizar a las personas contagiadas y establecer con quiénes estas estuvieron en contacto, mediante aplicaciones digitales en los celulares que preserven su anonimato, requiere de cuidadosos desarrollos de software por parte de grupos tecnológicos experimentados. 
A pesar de la dificultad de los modelos matemáticos para hacer predicciones precisas del curso de la enfermedad - se alimentan de parámetros que solo se pueden estimar imprecisamente-, la ciencia y la tecnología de alto nivel resultan insoslayables para combatir la pandemia.

Quienes sostienen lo contrario no han ofrecido alternativas y solo se han limitado a expresar un escepticismo basado más en su propio desconocimiento que en razones que lo confirmen.

\section{Cambios transitorios y cambios permanentes}

Para discernir si los cambios introducidos por la pandemia en la dinámica de las sociedades son de carácter transitorio o permanente es necesario recurrir a aquellos rasgos de nuestra mente que inciden directamente en ello.

Los seres humanos poseemos dos modos de procesar información, uno rápido y uno lento, según el psicólogo y Premio Nobel de Economía Daniel Kahneman (Kahneman, 2011). El sistema rápido es el que reacciona emocionalmente a las pistas que nos entrega el entorno. Nos induce a actuar instantáneamente en la dirección de esa particular emoción, conforme a la arquitectura neuronal de nuestro sistema nervioso central. El sistema lento, en cambio, nos lleva a examinar más pausadamente las situaciones, haciendo un cálculo de sus costos y beneficios, para con esos antecedentes tomar nuestras decisiones. Dicho de otro modo, atiende a las consecuencias de nuestros actos.

Por su parte, el filósofo moral y psicólogo experimental Joshua Greene (Greene, 2013) ha construido un correlato en el plano moral a partir de esa misma idea. Afirma Greene que nuestra mente posee dos modos para emitir juicios morales. Uno, el rápido y emocional. Este responde a nuestros sentimientos morales, que, de acuerdo a Greene, corresponden a la respuesta evolutiva para promover la colaboración al interior de los grupos. Esa adaptación es la que permitió evitar la "tragedia de los comunes", el conocido experimento mental propuesto por el ecologista Garret Hardin en 1968, ilustrativo de la tragedia que genera la ausencia de cooperación en un grupo de pastoralistas que tiene un limitado terreno para que paste su ganado. El lento, por su parte, corresponde al "cálculo moral" que hacemos cuando evaluamos las consecuencias de los actos propios o de terceros, es decir, cuando balanceamos los costos y beneficios de estos, y luego emitimos nuestro juicio moral.

Hay buenas razones evolutivas para que ambos se hayan seleccionado. Greene usa la metáfora de una máquina fotográfica para explicarlo. El modo "automático" permite tomar rápidamente una foto cuando se quiere aprovechar un instante 
imperdible. El modo "manual" permite ajustar cuidadosamente los parámetros del lente para mejorar el resultado en caso de que haya tiempo para hacerlo. Reacción instantánea o análisis pausado; sentimientos morales o cálculo moral.

En la extensa literatura sobre el dilema del trolley ${ }^{1}$, cuidadosos experimentos que utilizan resonancia magnética funcional muestran que los juicios morales emotivos involucran a zonas del cerebro distintas de las que se activan cuando se hace un cálculo de las consecuencias del acto bajo escrutinio (Greene, 2013). Esto tiene implicancias al momento de analizar los cambios que la pandemia pueda generar en la sociedad.

Quienes han anticipado que, luego de haber padecido las penurias de la pandemia, las personas sufrirán un cambio sustancial en su comportamiento y que, como resultado de ello, se harán más solidarias, más austeras, menos consumistas o con mayor consciencia social, no han considerado que esas reacciones emocionales tenderán a desaparecer una vez que la causa que las provocó - la pandemia - se atenúe o extinga.

Para que cambios que involucran rasgos permanentes de la naturaleza humana efectivamente ocurran, debería modificarse el genotipo de la especie. Solo así podría la arquitectura neuronal del sistema nervioso central sufrir un cambio sustantivo que modifique de manera permanente sus patrones de reacción emocional.

En cambio, aquellos impactos de la pandemia procesados por el sistema lento, cuyos beneficios son calculados como mayores que sus costos a través del tiempo, tenderán a ser más permanentes.

Así, el uso de tecnologías de información para sustituir reuniones presenciales por reuniones virtuales, intra o interorganizaciones, o para realizar actividades educativas a distancia o para efectuar atenciones de salud por telemedicina, todas las cuales han probado ser costo-eficientes, probablemente se transformarán en permanentes.

Se trata de cambios que se insinuaban con anterioridad a la pandemia, pero que ahora se verán acelerados fuertemente por sus beneficios asociados, los que fueron calculados y procesados pausadamente, sin la emocionalidad del sistema rápido.

1. Un carro de tren está bajando sin control a gran velocidad e impactará y matará a cinco personas. Los sujetos del experimento mental pueden, en un caso, empujar desde un puente a una persona muy obesa, que interrumpirá su carrera, salvando a las cinco personas pero matando a la que fue empujada, o, en otro caso, mover una palanca que desviará al carro a una vía distinta, también salvando a las cinco personas, pero matando a una que se encontraba reparando esa vía. 


\section{MODELO DE DESARROLLO DESPUÉS DE LA PANDEMIA}

En la explicación del marco conceptual utilizado para este ensayo presenté antecedentes relativos al origen evolucionario de la naturaleza humana y al patrón común que ha seguido la humanidad desde las bandas cazadoras-recolectoras originales hasta la actual sociedad del conocimiento. Ahí destacan dos elementos que deben ser atendidos al momento de pensar en las mejores maneras de impulsar el desarrollo del país.

Por una parte, está el permanente objetivo de las comunidades organizadas de seres humanos de mejorar las condiciones de vida de sus miembros y, por otra, la necesidad de contar con instituciones que reglen la interacción de estos, a fin de que el primer objetivo se logre de la manera más plena posible. Ambos están íntimamente relacionados.

En efecto, para crear valor, las personas actúan impulsadas tanto por disposiciones egoístas, que mejoran su situación personal, como altruistas, que benefician al resto; asimismo, ese esfuerzo creador se ve retroalimentado porque si son exitosos, sus protagonistas consiguen elevar su estatus, cualquiera que sea la vara con que este se mida, y la búsqueda de estatus es otro de los impulsores de nuestro comportamiento. Ese éxito puede darse en el ámbito de los negocios, de la ciencia, del arte, de la educación, del deporte, del trabajo o del vecindario, entre tantas otras opciones. Pero para incentivar que ello ocurra es necesario que las instituciones que regulan la vida social sean las adecuadas. De ahí la relación entre los rasgos de la naturaleza humana y las instituciones que reglamentan su interacción.

En otras palabras, el desarrollo precisa, como condición necesaria, aunque ciertamente no suficiente, dos factores: el primero, que las personas puedan desplegar sus talentos, anhelos y metas con la mayor libertad posible, para que el proceso de creación de valor efectivamente ocurra con el ímpetu requerido; y el segundo, que las instituciones que regulan su actuar se acomoden a ese hecho, asegurándose adicionalmente de que el beneficio de ese proceso de creación de valor, además de llegar a quienes fueron sus autores, no deje fuera al resto de la sociedad. Esto último no resulta trivial. Si como resultado de querer repartir los frutos de ese proceso se ponen trabas a las personas para que se sientan motivadas para crearlo, entonces las reglas así instituidas serán un obstáculo al desarrollo de la sociedad más que un impulsor de este.

Aquí se encuentra el meollo del debate contemporáneo. Determinar cuál es el conjunto de reglas capaces de incentivar la creación de valor y que, simultáneamente, exista preocupación por que quienes no resulten ganadores en ese proceso reciban la ayuda que contrarreste su disminuida o vulnerable condición, sin que 
eso entorpezca la necesaria creación de valor, constituye uno de los importantes desafíos pendientes de resolver en el mundo contemporáneo.

El origen del problema está en la naturaleza humana. El proceso de selección natural que condujo a su aparición no es susceptible de ser corregido culturalmente, porque se encuentra anclado genotípicamente. El simple expediente de instituir reglas creadas por la imaginación voluntarista de filósofos morales o ingenieros sociales, basadas en nobles sentimientos altruistas, no lo consigue. La historia del siglo XX así lo atestigua. Ni manipular ni fijar los precios para lograr que estos no afecten a los más vulnerables da los resultados esperados, ni tampoco decretar inamovilidad laboral protege el empleo; del mismo modo, prohibir la religión en la URSS no modificó las creencias de sus adherentes ni la separación de los hijos menores de sus padres en los kibbutzim israelíes mejoró su educación, como sus impulsores pretendían.

Los sesgos que nos impone la naturaleza humana desincentivan a los agentes a vender a precios fijados por debajo del que otros clientes están dispuestos a pagar, a contratar trabajadores si luego no pueden desvincularlos, a modificar creencias religiosas que están en la mente solo porque alguien lo ordenó o a remplazar el cariño o el cuidado de los padres por el de terceros. Por eso, las construcciones sociales basadas en suponer cambios en la naturaleza de las personas mediante cambios en el entorno cultural al que se enfrentan no han tenido éxito, y difícilmente lo tendrán en el futuro. La ilusión del surgimiento de un "hombre nuevo" se basa en la equivocada creencia de que el sistema nervioso central con que nace una persona es una "tabula rasa", y que su tránsito a la adultez solo está determinado por lo que aprenda culturalmente a lo largo de su vida (Pinker, 2003). El fracaso de Mao en lograrlo mediante la revolución "cultural" que intentó impulsar es solo una prueba más de que no es posible.

El diseño de las instituciones que regulan la interacción social debe, por el contrario, utilizar las fuerzas de la naturaleza humana más que combatirlas si lo que busca es obtener beneficios sociales. La metáfora del judoka es ilustrativa. Para voltear a su adversario, el judoka no combate la fuerza de aquel sino que la aprovecha en su favor. Pero las fuerzas de la naturaleza humana también generan costos. De ahí lo difícil que resulta acertar con la ecuación apropiada, que tanto incentive la obtención de beneficios como mitigue la inevitable aparición de costos. La política responsable estará siempre marcada por el afanoso esfuerzo por encontrar ese balance.

Para extraer valor de la disposición natural de las personas por beneficiarse a sí mismas se requiere de instituciones que permitan que agentes económicos privados intercambien bienes y servicios en mercados competitivos. Eso genera más bienes 
para más personas a mejores precios. La "mano invisible” de Adam Smith, que está detrás de ese efecto, funciona no porque él la haya así denominado, sino porque es el resultado de la acción de las fuerzas de la naturaleza humana que no requieren de instrucciones externas ni de coordinación centralizada para motivar a las personas. $\mathrm{Y}$ aunque es tremendamente contraintuitiva - personas actuando de manera individualista generan beneficios sociales sin que esa haya sido su intención-, es uno de los hallazgos más importantes de las ciencias sociales.

Sin embargo, como producto de esa beneficiosa competencia, no todos resultan ganadores. También hay perdedores. Adicionalmente, quienes emprenden actividades productivas y, por lo tanto, quienes corren más riesgos, reciben, en promedio, retornos más altos que los que escogen no correrlos y prefieren recibir regularmente un salario. Eso da lugar a desigualdades que pueden trasladarse con facilidad a otros ámbitos de la vida social, como la educación y la salud, lo que induce a su perpetuación. De allí que las sociedades procuren que ese tipo de servicios se otorguen con una similar calidad para todos sus integrantes, de modo que se multiplique el número de agentes con las habilidades necesarias para generar valor. Aun así, hay personas que sufren infortunios o nacen en condiciones desventajosas, lo que hace muy difícil que resulten ganadoras en situaciones de competencia. Los sentimientos morales, también parte de la naturaleza humana, nos instan a ayudarlos, y las sociedades modernas se sienten compelidas a instituir políticas públicas que vayan en su auxilio.

El egoísmo y el altruismo son necesarios para que las sociedades humanas se desarrollen en plenitud. El egoísmo propulsa la creación de valor, el altruismo cimenta el tejido social. Aprovecharlos adecuadamente seguirá siendo el ineludible dilema que las sociedades modernas deben intentar resolver. Como dijo el Premio Nobel de Economía Friedrich Von Hayek, utilizar las reglas impersonales del mercado en nuestras relaciones cercanas destruye el tejido social que nos entrelaza como sociedad y, por el contrario, solo utilizar las reglas con las que nos relacionamos con nuestros seres cercanos, como nuestros sentimientos morales nos instan a hacer, impide generar el valor y la riqueza que las sociedades requieren para satisfacer las crecientes necesidades de su población (Von Hayek, 1988).

Elucubraciones abstractas y teóricas que no se hacen cargo de la arquitectura de nuestro sistema nervioso central y los sesgos conductuales a que ella nos conduce tienden a generar reglas inapropiadas para alcanzar el desarrollo. Procurar compatibilizar dichas reglas con la esencia de lo humano define el corazón de la dificultad a la que nos enfrentamos.

No es el propósito de quien escribe ni es este el espacio para proponer formas de resolverla. 


\section{Pandemia y desarrollo}

Una de las premisas en las que basa este ensayo se funda en el carácter evolucionario de nuestros rasgos esenciales, los que no han sufrido modificaciones importantes desde nuestra época de cazadores-recolectores. Leda Cosmides, quien acuñó el término psicología evolucionaria, lo expresa así: "nuestro cráneo alberga una mente de la Edad de Piedra" (Cosmides y Tooby, 1997). Ni la pandemia de Covid-19 ni las anteriores que ha sufrido la humanidad han modificado ese hecho. Si las personas no han cambiado su sistema cognitivo ni el emocional ni su psicología moral producto de ella, no se aprecian razones para que la aparición del Covid-19 requiera, per se, introducir modificaciones a nuestro modelo de desarrollo. $\mathrm{Y}$ aunque la pandemia ha causado profundos trastornos en la salud de quienes se contagiaron e incluso la muerte, en los casos más extremos, y además ha provocado un doloroso impacto en las condiciones de vida de vastos sectores de la población, ello corresponde a situaciones que deben ser abordadas con medidas ad hoc de corto plazo y, por lo tanto, no forman parte de la estrategia de largo plazo que orienta nuestro modelo.

Sin embargo, la pandemia sí ha generado impactos de largo plazo, y es respecto de ellos que nuestro modelo de desarrollo requiere adaptarse. Los consigné en la sección correspondiente: constatación de la extrema interconexión de la economía, importancia de la sociedad del conocimiento en lo que viene y cambios tecnológicos específicos, cuya introducción se ha visto acelerada por efecto de la pandemia.

\section{Realismo económico}

La intrincada interconexión de las economías modernas - invisible para la mayoría de la población, absorta en rutinas circunscritas al ámbito de sus intereses y los de sus cercanos- nos alerta a modificar el enfoque con el que se examine nuestro modelo de desarrollo futuro.

La extremada imbricación de la economía y el hecho de que su funcionamiento requiere aprovechar aquellos rasgos de la naturaleza humana que favorecen la creación de valor - incentivos, búsqueda de estatus, competencia- hacen que nuestro modelo de desarrollo futuro, una vez superada la pandemia, deba necesariamente atender a ambos hechos.

$\mathrm{Si}$, por el contrario, se adopta un enfoque "normativo" para determinar el modelo de desarrollo, habrá una menor probabilidad de éxito. Ello, porque no basta con explicitar objetivos "moralmente" deseables a conseguir - derechos sociales, educación de calidad o combate a la desigualdad-, sino que es necesario, además, hacerse cargo con realismo de la manera en que las personas se comportan 
conforme a su naturaleza, para, a partir de eso, proponer las políticas públicas que permitan alcanzarlos. Si se piensa que los individuos se comportan como quienes propugnan el enfoque normativo desearían que lo hicieran, volveremos a frustrar las expectativas de las nuevas generaciones.

El realismo con que se aborde el funcionamiento de la economía al momento de diseñar un modelo de desarrollo, así como las políticas públicas que lo acompañen, será un elemento crucial para no quedar atrapados en la "trampa de los ingresos medios", la que sería nefasta para las aspiraciones de la ciudadanía. Esta pandemia ha ayudado a dejarlo claro.

\section{Plena incorporación a la sociedad del conocimiento}

Como argumenté previamente, esta pandemia ha ratificado la importancia que para combatirla han tenido - y seguirán teniendo- la ciencia y la tecnología. Pero esa importancia tiene una razón más profunda, la que también ha estado presente a lo largo de este ensayo.

La ciencia y la tecnología son el sustento en el que se basa la creación de valor en las sociedades contemporáneas, que se obtiene "empaquetando" el conocimiento inmerso en ellas. Más aun, es la tetralogía compuesta por ciencia, tecnología, innovación y emprendimiento, todas ellas interconectadas, la manera moderna de aprovechar integralmente el conocimiento para propulsar el desarrollo de los países. Esto es plenamente válido para Chile.

En efecto, esa tetralogía constituye un verdadero "arpegio", esas cuatro notas musicales que tocadas en cualquier orden suenan armónicas. La ciencia crea conocimiento, la tecnología lo aplica, la innovación obtiene valor a partir de ellas y el emprendimiento implementa productivamente todo lo anterior. Se interrelacionan de distintas maneras y se articulan en cualquier orden. La conformación de un "ecosistema" a partir ellas, cuyos nodos tengan cada vez mayor calidad y cuyas conexiones sean cada vez más frondosas y robustas, debería estar en el centro de una estrategia para insertar plenamente a Chile en la sociedad del conocimiento. El Consejo Nacional de Ciencia, Tecnología, Conocimiento e Innovación que presido publicó un White Paper en diciembre de 2019 en el que se detallan los aspectos que una estrategia de este tipo debe contemplar².

Chile cuenta con condiciones particularmente favorables para lograrlo: los dos extremos de su territorio son atractores de ciencia y tecnología de punta de clase

2. Ver http://www.cnid.cl/wp-content/uploads/2019/12/CTCI-para-Chile-y-Contexto-para-lareflexion_web.pdf 
mundial por las condiciones únicas e irrepetibles que poseen: astronomía, desierto de Atacama y energía solar en el norte; y ecosistemas marítimo-terrestres y puerta de entrada a la Antártica en el sur. Ellos facilitan construir una imagen-país, para sus ciudadanos y para el mundo, orientada en esa dirección.

\section{Digitalización y virtualización}

Lo que esta pandemia ha provocado es una aceleración del proceso de digitalización que el mundo ha estado experimentado. En particular, esto se ha manifestado con especial fuerza a través de la virtualización de los contactos interpersonales en una multitud de ambientes: familias, organizaciones productivas, reparticiones de gobierno, ONG y también en el crucial mundo educativo, clave para alcanzar una pujante sociedad del conocimiento. El uso intensivo de esas herramientas - genéricamente denominadas "oficinas virtuales"- se apoya no solo en el distanciamiento social que la pandemia ha requerido, sino especialmente, al constatar la facilidad de su uso, en lo costo-eficiente que resultan, en el ahorro de tiempo y costos de traslado que implican, y en la posibilidad de grabar automáticamente su contenido y manejar estadísticas acumuladas de lo que en ellas ocurre.

Ese impacto, al que debe agregarse la profundización de la sociedad del conocimiento que el combate a la pandemia ha inducido, implica cambios paradigmáticos en la forma y frecuencia con que se realice el transporte en el futuro, además de una paulatina disminución en el uso de infraestructura física para las actividades "virtualizadas". Como contrapartida, se requerirá crecientemente más energía para enviar, almacenar y manipular la gigantesca cantidad de datos que la digitalización y la virtualización requieren, la que seguramente se generará de maneras no convencionales. Chile posee en abundancia fuentes de energía solar, eólica o de corrientes marinas, y además cuenta con una gran cantidad de litio, necesario para el crucial almacenamiento de energía.

Nuestro modelo de desarrollo deberá tener la capacidad de adaptarse rápidamente a estos nuevos escenarios. Esto precisa de un sector privado pujante, que dé lugar a múltiples actores, para que, emprendiendo en paralelo, asuman los riesgos inherentes a probar innovaciones. Quienes fracasen afectarán solo a su grupo, y quienes sean exitosos podrán socializar su hallazgo mediante el intercambio o la imitación. Utilizar el aparato estatal para efectuar esas adaptaciones no es una buena idea. Además de sus rigideces burocráticas, un solo actor que tome riesgos produce un resultado binario: éxito o fracaso, y si se fracasa, fracasan todos, con la consiguiente pérdida de los recursos de todos. 
Pensar nuestro futuro modelo de desarrollo a partir del impacto que ha tenido la pandemia implica ser realistas y no normativos en materia económica, requiere insertarse plenamente en la sociedad del conocimiento y precisa estimular la existencia de un sector privado pujante, que introduzca las adaptaciones necesarias que acomoden los cambios tecnológicos que la pandemia ha acelerado.

El fundamento de la tesis aquí propuesta se apoya en la existencia de la naturaleza humana de la manera en que la presenté y en la constatación de que la creación de valor ha sido una constante universal en la trayectoria de la historia humana. Ambas afirmaciones son desafiables. La convicción que tengo de su validez y pertinencia están presentadas con mayor fundamentación en De naturaleza liberal (Fischer, 2018), basado en los desarrollos teóricos de una multitud de investigadores, así como de la evidencia empírica que ellos han provisto. 


\section{REFERENCIAS}

Boyer, Pascal (2001). ¿Por qué tenemos religión? Origen y evolución del pensamiento religioso, Cuidad de México, Taurus. [Religion explained. The evolutionary origins of religious beliefs, Nueva York, Basic Books, 2001].

Cosmides, Leda y John Tooby (1988). "The evolution of war and its cognitive foundations, Institute for Evolutionary Studies", Technical report 88-1.

Cosmides, Leda y John Tooby (1992). "Cognitive adaptations for social exchange". En: Cosmides, Tooby y Jerome Barkow, eds., The adapted mind, Nueva York, Oxford University Press (1992), "The psychological foundations of culture". En: The adapted mind.

Cosmides, Leda y John Tooby (1992). "The psychological foundations of culture". En: Cosmides, Tooby y Jerome Barkow, eds., The adapted mind, Nueva York, Oxford University Press (1992).

Cosmides, Leda y John Tooby (1997). "Evolutionary psychology: a primer”, Center for Revolutionary Psychology, U. California at Santa Barbara.

Fischer, Álvaro (2018). De naturaleza liberal, Santiago, Catalonia.

Greene, Joshua (2013). Moral tribes, Penguin Press.

Haidt, Jonathan (2012). The righteous mind, Penguin Random House.

Kahneman, Daniel (2011). Thinking fast and slow, Nueva York, Farrar, Strauss and Giroux.

Mosterín, Jesús (2008). La naturaleza bumana (nueva edición de bolsillo, corregida y renovada, en la colección Austral). Madrid: Espasa Calpe.

Pinker, Steven (1995). How the mind works, nueva edición, Nueva York, Norton \& Co. [Cómo funciona la mente, Barcelona, Destino, 2007].

Pinker, Steven (2003). The blank slate: the modern denial of buman nature. London, Penguin Books.

Smith, Adam (2009b). Una investigación sobre la naturaleza y causas de la riqueza de las naciones, Madrid, Tecnos.

Smith, Vernon, Elizabeth Hofmman y Kevin McCabe (1998). "Behavioral foundations of reciprocity: experimental economics and evolutionary psychology", Economic Inquiry 36, 3: 335-352. Oxford University Press.

Sykes, Brian (2005). La maldición de Adán. Elfuturo de la bumanidad masculina, Barcelona, Debate. 
Tudge, Colin (1998). Neanderthals, bandits and farmers: how agriculture really began, Londres, Weidenfeld \& Nicolson/New Haven, CT, Yale University Press, 1999. [Neandertales, bandidos y granjeros. Como surgió realmente la agricultura, Barcelona, Crítica, 2000].

Von Hayek, Friedrich (1988). The fatal conceit, University of Chicago Press.

Wilson, Edward O. (1998). Consilience: the unity of knowledge, Nueva York, Knopf. [Consilience: la unidad del conocimiento, Barcelona, Galaxia Gutenberg/Círculo de Lectores, 1999].

Wilson, Edward O. (2014). The meaning of buman existence, New York, Liveright Books. 